\title{
ON WEAKLY NONLINEAR CONTRACTIONS
}

\author{
By Kun-Jen Chung
}

The purpose of this paper is to generalize some known fixed point theorems to cone-value metric spaces.

\section{(I) Definitions}

Let $E$ be a normed space. A set $K \subset E$ is said to be a cone if (i) $K$ is closed (ii) if $u, v \in K$ then $a u+b v \in K$ for all $a, b \geqq 0$, (iii) $K \cap(-K)=\{\theta\}$ where $\theta$ is the zero of the space $E$, and (iv) $K^{\circ} \neq \emptyset$, where $K^{\circ}$ is the interior of $K$. We say $u \geqq v$ if and only if $u-v \in K$, and $u>v$ if and only if $u-v \in K$ and $u \neq v$.

The cone $K$ is said to be strongly normal if there is $\delta>0$ such that if $z=\sum_{\imath=1}^{n} b_{i} x_{\imath}$, $x_{i} \in K,\left\|x_{i}\right\|=1, \sum_{i=1}^{n} b_{\imath}=1, b_{i} \geqq 0$ implies $\|z\|>\delta$. The norm in $E$ is said to be semimonotone if there is a numerical constant $M$ such that $\theta \leqq x \leqq y$ implies $\|x\| \leqq M\|y\|$ (where the constant $M$ does not depend on $x$ and $y$ ).

Let $X$ be a set and $K$ a cone. A function $d: X \times X \rightarrow K$ is said to be a $K$ metric on $X$ if and only if (i) $d(x, y)=d(y, x)$, (ii) $d(x, y)=\theta$ if and only if $x=y$, and (iii) $d(x, y) \leqq d(x, z)+d(z, y)$. A sequence $\left\{x_{n}\right\}$ in a $K$-metric space $X$ is said to converge to $x_{0}$ in $X$ if and only if for each $u \in K^{\circ}$ there exists a positive integer $N$ such that $d\left(x_{n}, x_{0}\right) \leqq u$ for $n \geqq N$. A sequence $\left\{x_{n}\right\}$ in $X$ is Cauchy if and only if for each $u \in K^{\circ}$ there exists a positive integer $N$ such that $d\left(x_{n}, x_{m}\right) \leqq u$ for $n, m \geqq N$. The $K$-metric space $(X, d)$ is said to be complete if and only if every Cauchy sequence in $X$ converges. Let $S$ be a subset of $X$; a point $x \in X$ is adherent to $S$ if there is a sequence of points of $S$ converging to $x$. The set of the points of $X$ adherent to $S$ is called the closure of $S$. The set $S$ is closed if and only if it is equal to its closure. A point in $X$ is a boundary point of $S$ if it is adherent to both $S$ and its complement $C(S)$. The boundary of $S$, denoted by $\partial S$, is the set of its boundary points.

Throughout the rest of this paper we assume that $K$ is strongly normal, that $E$ is a reflexive Banach space, that $(X, d)$ is a complete $K$-metric space, that $P(S)=\{d(x, y) ; x, y \in S\}$ where $S$ is a subset of $X$, that $\bar{P}(S)$ denotes the weak closure of $P(S)$, and that $P_{1}(S)=\{z ; z \in \bar{P}(S)$ and $z \neq \theta\}$.

Many preliminary results and examples which will be used in our theorems, are listed in $[4,8]$.

Received June 12, 1982 


\section{(II) Main results}

Definition 1. The mapping $\emptyset: P_{1}(S) \rightarrow K$ is said to be upper semicontinuous if $\left\{u_{n}\right\}$ and $\left\{\emptyset u_{n}\right\}$ are both weakly convergent, then $\lim _{n \rightarrow \infty} \emptyset u_{n} \leqq \emptyset\left(\lim _{n \rightarrow \infty} u_{n}\right)$.

Definition 2. Let $S \subset X$. We say that a mapping $T: S \rightarrow X$ satisfies Condition (A) if for each $x \in S$ there exists an element $u$ of $S$ such that $d(x, u)+$ $d(u, T x)=d(x, T x)$.

Let $x_{0} \in S$. We shall construct two sequences $\left\{x_{n}\right\}$ and $\left\{x_{n}^{\prime}\right\}$ as follows: Define $x_{1}^{\prime}=T x_{0}$. If $x_{1}^{\prime} \in S$, set $x_{1}=x_{1}^{\prime}$. If $x_{1}^{\prime} \notin S$, choose $x_{1} \in S$ so that $d\left(x_{0}, x_{1}\right)$ $+d\left(x_{1}, x_{1}^{\prime}\right)=d\left(x_{0}, x_{1}^{\prime}\right)$. Set $x_{2}^{\prime}=T x_{1}$. If $x_{2}^{\prime} \in S$, set $x_{2}=x_{2}^{\prime}$. If not, choose $x_{2} \in S$ so that $d\left(x_{1}, x_{2}\right)+d\left(x_{2}, x_{2}^{\prime}\right)=d\left(x_{1}, x_{2}^{\prime}\right)$. Continuing in this manner, we obtain $\left\{x_{n}\right\},\left\{x_{n}^{\prime}\right\}$ satisfying

(i) $x_{n+1}^{\prime}=T x_{n}$,

(ii) $x_{n}=x_{n}^{\prime}$ if $x_{n}^{\prime} \in S$, and

(iii) $x_{n} \in S$ and $d\left(x_{n-1}, x_{n}\right)+d\left(x_{n}, x_{n}^{\prime}\right)=d\left(x_{n-1}, x_{n}^{\prime}\right)$ if $x_{n}^{\prime} \notin S$.

Let $Q\left(x_{0}\right)=\left\{x_{i} \in\left\{x_{n}\right\} ; x_{\imath} \neq x_{i}^{\prime}\right\}$ and $F\left(x_{0}\right)=\left\{x_{i} \in\left\{x_{n}\right\} ; x_{i}=x_{i}^{\prime}\right\}$.

The following is our main result which is comparable to Theorem 2.2 of Caristi [9] and Theorem 1 of Park and Yoon [18].

Lemma 1. Let $(X, d)$ be a complete K-metric space and $S$ a nonempty closed subset of $X$. Suppose that $T: S \rightarrow X$ satisfies Condition (A), (1), (2) and (3).

(1) $d(T x, T y) \leqq \emptyset(d(x, y)), x \neq y \in S$,

(2) $\emptyset(t)<t$ for any $t \in P_{1}(S)$, where $\emptyset: P_{1}(S) \rightarrow K$ is upper semicontinuous,

(3) $x_{n} \in Q\left(x_{0}\right)$ implies $x_{n-1}, x_{n+1} \in F\left(x_{0}\right)$, where the sequence $\left\{x_{n}\right\}$ defined as above. Then $T$ has a unique fixed point in $S$.

Proof. If there exists an integer 3 such that $x_{n}$ lies in $S$ for all $n \geqq j$, Chung [8] showed that this sequence of iterates converges to a fixed point of $T$. Hence we may assume that $Q\left(x_{0}\right)$ contains infinitely many points. Let $Q\left(x_{0}\right)=\left\{x_{n(k)}\right\}$.

We assert that

(B) $\left\{d\left(x_{n}, x_{n+1}\right)\right\}$ weakly converges to $\theta$ as $n \rightarrow \infty$,

and

(C) $\left\{d\left(T\left(x_{n}\right), x_{n}\right)\right\}$ weakly converges to $\theta$ as $n \rightarrow \infty$.

To prove $(\mathrm{B})$ and $(\mathrm{C})$ we first prove that

(G) $d\left(x_{n(k)-1}, x_{n(k)}^{\prime}\right)$ weakly converges to $\theta$ as $k \rightarrow \infty$.

If we put $n(k+1)=s, n(k)=r$, then it follows that 


$$
\begin{aligned}
& d\left(x_{s-1}, x_{s}^{\prime}\right)=d\left(T\left(x_{s-2}\right), T\left(x_{s-1}\right)\right) \\
& \leqq \emptyset\left(d\left(x_{s-2}, x_{s-1}\right)\right) \\
& \leqq d\left(x_{s-2}, x_{s-1}\right) \leqq \cdots \leqq d\left(x_{r}, x_{r+1}\right) \\
& \leqq d\left(x_{r}, x_{r}^{\prime}\right)+d\left(x_{r}^{\prime}, x_{r+1}\right) \\
& \leqq d\left(x_{r}, x_{r}^{\prime}\right)+d\left(x_{r-1}, x_{r}\right) \\
& =d\left(x_{r-1}, x_{r}^{\prime}\right) \text {. }
\end{aligned}
$$

Therefore $\left\{d\left(x_{n(k)-1}, x_{n(k)}^{\prime}\right)\right\}$ and $\left\{d\left(x_{n(k)-2}, x_{n(k)-1}\right)\right\}$ are decreasing and bounded. Let $\left\{d\left(x_{m(i)}, x_{m(i)+1}^{\prime}\right)\right\}$ be a subsequence of $\left\{d\left(x_{n(k)-1}, x_{n(k)}^{\prime}\right)\right\}$. There exist subsequences $\left\{d\left(x_{s(i)}, x_{s(i)+1}^{\prime}\right)\right\}$ of $\left\{d\left(x_{m(i)}, x_{m(i)+1}^{\prime}\right\}\right.$ and $\left\{d\left(x_{s(i)-1}, x_{s(i)}\right)\right\}$ of $\left\{d\left(x_{m(i)-1}, x_{m(i)}\right)\right\}$ such that $\left\{d\left(x_{s(i)}, x_{s(i)+1}^{\prime}\right)\right\}$ weakly converges to $z \in K$ and $\left\{d\left(x_{s(i)}, x_{s(i)-1}\right)\right\}$ to $t \in K$. From the fact $d\left(x_{s-1}, x_{s}^{\prime}\right) \leqq d\left(x_{s-2}, x_{s-1}\right) \leqq d\left(x_{r-1}, x_{r}^{\prime}\right)$, we see that $z=t$.

Because $\emptyset\left(d\left(x_{s-2}, x_{s-1}\right)\right) \geqq d\left(x_{s-1}, x_{s}^{\prime}\right)$ we see that $\left\{\emptyset\left(d\left(x_{s-1}, x_{s-2}\right)\right)\right\}$ is bounded. For convenience, we can assume that $\left\{\emptyset\left(d\left(x_{s(i)}, x_{s(i)-1}\right)\right)\right\}$ has a weak limit. By the upper semicontinuity, we have $\emptyset(z) \geqq z$. Therefore $z=\theta$ and $(G)$ holds.

If $n(k)<n \leqq n(k+1)$, we have

$$
d\left(x_{n(k+1)-1}, x_{n(k+1)}^{\prime}\right) \leqq d\left(x_{n}, x_{n+1}\right) \leqq d\left(x_{n(k)-1}, x_{n(k)}^{\prime}\right) .
$$

Therefore (B) holds. From (B) and $(G)$, we see that $(C)$ holds, too.

Now we show that the sequence $\left\{x_{n}\right\}$ is Cauchy. Suppose not. Then there is an $\varepsilon \in K^{\circ}$ such that for every integer $\imath$, there exist integers $\underline{n}(i), \underline{m}(i)$ with $\imath \leqq \underline{n}(i)<\underline{m}(i)$ such that

(4) $d\left(x_{\underline{n}(i)}, x_{\underline{m}(i)}\right) \$ \underline{\varepsilon}$.

Let, for each integer $i, \underline{m}(i)$ be the least integer exceeding $\underline{n}(i)$ satisfying (4); that is

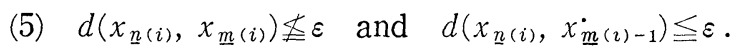

Since $K$ is semimonotone, the sequence $\left\{d\left(x_{\underline{n}(i)}, x_{\underline{m}(i)-1}\right)\right\}$ is bounded. For convenience, we let $\left\{d\left(x_{\underline{n}(i)}, x_{\underline{m}(i)}\right)\right\}$ weakly converges to $z$. Since

(E) $\left\{\begin{array}{l}d\left(T\left(x_{\underline{\underline{n}}(i)}\right), T\left(x_{\underline{m}(i)}\right)\right) \leqq d\left(x_{\underline{\underline{n}}(i)}, T\left(x_{\underline{\underline{n}}(i)}\right)\right)+d\left(x_{\underline{n}(i)}, x_{\underline{m}(i)}\right)+d\left(x_{\underline{m}(i)}, T\left(x_{\underline{m}(i)}\right)\right), \\ d\left(x_{\underline{n}(i)}, x_{\underline{m}(i)}\right) \leqq d\left(x_{\underline{n}(i)}, T\left(x_{\underline{n}(i)}\right)\right)+d\left(T\left(x_{\underline{\underline{n}}(i)}\right), T\left(x_{\underline{m}(i)}\right)\right)+d\left(T\left(x_{\underline{m}(i)}\right), x_{\underline{m}(i)}\right),\end{array}\right.$

we see that $\left\{d\left(T\left(x_{\underline{n}(i)}\right), T\left(x_{\underline{m}(i)}\right)\right)\right\}$ weakly converges to $z$. If $z \neq \theta$, we have

(6) $\quad d\left(T\left(x_{\underline{\underline{n}}(i)}\right), T\left(x_{\underline{m}(i)}\right)\right) \leqq 0\left(d\left(x_{\underline{n}(i)}, x_{\underline{m}(i)}\right)\right)<d\left(x_{\underline{n}(i)}, x_{\underline{m}(i)}\right)$.

Let $\left\{\emptyset\left(d\left(x_{\underline{n}(i)}, x_{\underline{m}(i)}\right)\right)\right\}$ have a weak limit. Therefore we have $\emptyset(z) \geqq z$. We obtain $z=\theta$. The rest of the proof of the theorem is the same as that of theorem 
1 [8]. Therefore $\left\{x_{n}\right\}$ is a Cauchy sequence. By completeness, there is a $u \in S$ such that $\left\{x_{n}\right\}$ converges to $u$ in $S$, and $T u=u$. This completes the proof.

Definition 3. Let $S \subset X$. We say that a mapping $T: S \rightarrow X$ is metrically inward if for each $x \in S$ there exists an element $u$ of $S$ such that $d(x, u)+$ $d(u, T x)=d(x, T x)$ where $u=x$ if and only if $x=T x$.

It is clear that if $T$ is metrically inward, then $T$ satisfies Condition (A).

Definition 4. Let $(X, d)$ be a complete $K$-metric space. We call $(X, d)$ a complete $K$-metric convex space if for any real number $c, 0<c<1$, and any $x, y \in X$, there exists $z \in X$ such that $d(x, z)=c d(x, y)$, and $d(z, y)=(1-c) d(x, y)$.

LEMMA 2. If $S$ is a nonempty closed subset of the complete and convex $K$ metric space $(X, d)$ and of $p_{0} \in S$, and $p_{1} \in S$, then there exists a point $p$ in the boundary $\partial S$ of $S$ such that $d\left(p_{0}, p\right)+d\left(p, p_{1}\right)=d\left(p_{0}, p_{1}\right)$.

Proof. By Definition 4, we can choose a point $p_{2} \in X$ such that

$d\left(p_{0}, p_{2}\right)=d\left(p_{2}, p_{1}\right)=2^{-1} d\left(p_{0}, p_{1}\right)$ and $d\left(p_{0}, p_{2}\right)+d\left(p_{2}, p_{1}\right)=d\left(p_{0}, p_{1}\right)$.

Case 1: If $p_{2} \in S$, we choose $p_{3} \in X$ such that $d\left(p_{2}, p_{3}\right)=d\left(p_{3}, p_{1}\right)=$ $2^{-2} d\left(p_{0}, p_{1}\right)$ and $d\left(p_{2}, p_{3}\right)+d\left(p_{3}, p_{1}\right)=d\left(p_{2}, p_{1}\right)$. Since $d\left(p_{0}, p_{2}\right)+d\left(p_{2}, p_{3}\right)+$ $d\left(p_{3}, p_{1}\right)=d\left(p_{0}, p_{1}\right)$, and $d\left(p_{0}, p_{1}\right) \leqq d\left(p_{0}, p_{3}\right)+d\left(p_{3}, p_{1}\right)$, we have $d\left(p_{0}, p_{2}\right)+$ $d\left(p_{2}, p_{3}\right) \leqq d\left(p_{0}, p_{3}\right) \quad$ and $\quad d\left(p_{0}, p_{2}\right)+d\left(p_{2}, p_{3}\right)=d\left(p_{0}, p_{3}\right)$. We get $d\left(p_{0}, p_{3}\right)+$ $d\left(p_{3}, p_{1}\right)=d\left(p_{0}, p_{1}\right)$.

Case 2: If $p_{2} \notin S$, we choose $p_{3} \in X$ such that $d\left(p_{0}, p_{3}\right)=d\left(p_{3}, p_{2}\right)=2^{-2} d\left(p_{0}, p_{1}\right)$ and $d\left(p_{0}, p_{3}\right)+d\left(p_{3}, p_{2}\right)=d\left(p_{0}, p_{2}\right)$. Since $d\left(p_{0}, p_{3}\right)+d\left(p_{3}, p_{2}\right)+d\left(p_{2}, p_{1}\right)=d\left(p_{0}, p_{1}\right)$ and $d\left(p_{0}, p_{1}\right) \leqq d\left(p_{0}, p_{3}\right)+d\left(p_{3}, p_{1}\right)$, we have $d\left(p_{3}, p_{2}\right)+d\left(p_{2}, p_{1}\right) \leqq d\left(p_{3}, p_{1}\right)$, and $d\left(p_{3}, p_{2}\right)+d\left(p_{2}, p_{1}\right)=d\left(p_{3}, p_{1}\right)$. We get $d\left(p_{0}, p_{3}\right)+d\left(p_{3}, p_{1}\right)=d\left(p_{0}, p_{1}\right)$.

Continuing the above process, we can choose a sequence $\left\{p_{n}\right\} \subset X$ such that $d\left(p_{n}, p_{n+1}\right)=2^{-n} d\left(p_{0}, p_{1}\right)$ and $d\left(p_{0}, p_{n}\right)+d\left(p_{n}, p_{1}\right)=d\left(p_{0}, p_{1}\right)$. Let $p_{k(n)}$ be another point such that $p_{k(n)} \neq p_{n}$ and $d\left(p_{k(n)}, p_{n+1}\right)=2^{-n} d\left(p_{0}, p_{1}\right)$. Then either $p_{k(n)} \in S$ and $p_{n} \notin S$ or $p_{k(n)} \notin S$ and $p_{n} \in S$. By the construction of $\left\{p_{n}\right\}$, we see that $\left\{p_{n}\right\}$ is Cauchy. There exists a point $p \in X$ such that $\left\{p_{n}\right\}$ converges to $p$. We also know that $p \in \partial S$. Since $d\left(p_{0}, p_{n}\right)+d\left(p_{n}, p_{1}\right)=d\left(p_{0}, p_{1}\right)$ for all $n \geqq 1$, we have $d\left(p_{0}, p_{1}\right) \geqq d\left(p_{0}, p_{n}\right), d\left(p_{0}, p_{1}\right) \geqq d\left(p_{n}, p_{1}\right)$. Sequences $\left\{d\left(p_{0}, p_{n}\right)\right\}$ and $\left\{d\left(p_{n}, p_{1}\right)\right\}$ are bounded. Since $E$ is a reflexive Banach space, for convenience, let

$$
\left\{\begin{array}{l}
d\left(p_{0}, p_{n}\right) \text { weakly converge to } x, \text { and } \\
d\left(p_{n}, p_{1}\right) \text { weakly converge to } y
\end{array}\right.
$$

According to the triangular inequality, we have

(7) $d\left(p_{0}, p_{n}\right) \leqq d\left(p_{0}, p\right)+d\left(p, p_{n}\right)$,

(8) $d\left(p, p_{0}\right) \leqq d\left(p_{0}, p_{n}\right)+d\left(p_{n}, p\right)$, 
(9) $d\left(p_{n}, p_{1}\right) \leqq d\left(p_{1}, p\right)+d\left(p, p_{n}\right)$,

(10) $d\left(p_{1}, p\right) \leqq d\left(p_{1}, p_{n}\right)+d\left(p_{n}, p\right)$.

From (7), (8), (9), and (10), we see that $x \leqq d\left(p_{0}, p\right), d\left(p_{0}, p\right) \leqq x, y \leqq d\left(p_{1}, p\right)$, and $d\left(p_{1}, p\right) \leqq y$. By $(\mathrm{j})[8]$, we see that $d\left(p_{0}, p\right)+d\left(p, p_{1}\right)=d\left(p_{0}, p_{1}\right)$. This completes the proof.

Theorem 1. Let $(X, d)$ be a complete, convex, K-metric space and $S$ a nonempty closed subset of $X$. Suppose that $T: S \rightarrow X$ satisfies (1), (2) and (11).

(11) $T x \in S$ for every $x \in \partial S$.

Then $T$ has a unique fixed point in $S$.

Proof. We construct a sequence $\left\{p_{n}\right\}$ in $S$ as follows: Let $p_{0}$ be an arbitrary point in $S$. Let $p_{1}^{\prime}=T\left(p_{0}\right)$. If $p_{1}^{\prime} \in S$, then $p_{1}=p_{1}^{\prime}$, otherwise, by lemma 2 , we choose $p_{1} \in \partial S$ so that $d\left(p_{0}, p_{1}\right)+d\left(p_{1}, p_{1}^{\prime}\right)=d\left(p_{0}, p_{1}^{\prime}\right)$. Suppose that $\left\{p_{i}\right\}$, $\left\{p_{i}^{\prime}\right\}, i=1, \cdots, N$ have been chosen so that

(i) $p_{\imath}^{\prime}=T\left(p_{\imath-1}\right), i=1, \cdots, N$;

(ii) either $p_{2}=p_{\imath}^{\prime} \in S$ or $p_{i} \in \partial S$ and satisfies the relation:

$$
d\left(p_{\imath-1}, p_{i}\right)+d\left(p_{\imath}, p_{\imath}^{\prime}\right)=d\left(p_{\imath-1}, p_{\imath}^{\prime}\right) .
$$

Now set $p_{N+1}^{\prime}=T\left(p_{N}\right)$. If $p_{N+1}^{\prime} \in S$ we put $p_{N+1}=p_{N+1}^{\prime}$, otherwise we choose $p_{N+1} \in \partial S$ so that $d\left(p_{N}, p_{N+1}^{\prime}\right)=d\left(p_{N}, p_{N+1}\right)+d\left(p_{N+1}, p_{N+1}^{\prime}\right)$. Thus by induction we are finished.

By the construction of $\left\{p_{n}\right\},(11)$ implies that the sequence $\left\{p_{n}\right\}$ satisfies (3). Lemma 1 is applicable. Hence $T$ has a unique fixed point in $S$.

Theorem 2. Let $(X, d)$ be a complete K-metruc space and $S$ a nonempty closed subset of $X$. Suppose that $T: S \rightarrow X$ is metrically inward and that $T$ satisfies (1), (2) and (3). Then $T$ has a unique fixed point in $S$.

If $E$ is the set of all real numbers and if $K$ is the set of all nonnegative reals, then, from (4) and (6), Theorems 1 and 2 may now be restated in the following forms.

Theorem 3. Let $(X, d)$ be a complete, convex K-metric space and $S$ a non-

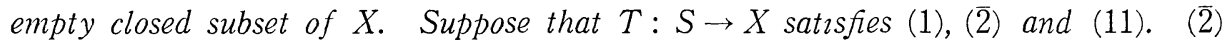
$\emptyset(t)<t$ for any $t \in P_{1}(S)$, where $\emptyset$ is upper semicontinuous from the right on $P_{1}(S)$. Then $T$ has a unique fixed point in $S$.

THEOREM 4. Let $(X, d)$ be a complete metric space and $S$ a nonempty closed subset of $X$. Suppose that $T: S \rightarrow X$ is metrically inward and that $T$ satisfies (1), (2), and (3). Then $T$ has a unique fixed point in $S$.

Utilizing the way of the proof of Lemma 2 [19], we have the following result. 
THEOREM 5. Let $(X, d)$ be a complete metric space and $S$ a nonempty closed subset of $X$. Suppose that $T$ is a mapping from $S$ into $X$. Then the following conditions are equivalent:

(i) For any $\varepsilon>0$, there exists $\delta(\varepsilon)>0$ such that $d(T x, T y)<\varepsilon$ whenever

$$
\varepsilon \leqq d(x, y)<\varepsilon+\delta(\varepsilon) \text { and } x, y \in S .
$$

(ii) There exısts a self-mapping 0 of $[0 \infty)$ into $\left[\begin{array}{ll}0 & \infty\end{array}\right]$ such that $\emptyset(s)<s$ for all $s>0$, where $\emptyset$ is upper semicontmuous from the right on $[0 \infty)$ and $d(T x, T y) \leqq \emptyset(d(x, y)), x, y \in S$.

From Theorem 5, we have the following results.

THEOREM 6. Let $(X, d)$ be a complete metrically convex space and $S$ a nonempty closed subset of $X$. Suppose that $T: S \rightarrow X$ satısfies (i) in Theorem 5 and (11). Then $T$ has a unique fixed point in $S$.

Theorem 6 was proved in [1] by Assad, but it is a special case of our Theorem 1.

THEOREM 7. Let $(X, d)$ be a complete metric space and $S$ a nonempty closed subset of $X$. Suppose that $T: S \rightarrow X$ is a metrically inward mapping satisfying (i) in Theorem 5 and (3). Then $T$ has a unıque fixed point in $S$.

Theorem 7 was proved in [18] by Park and Yoon, but it is a special case of our Theorem 2.

Many related papers can be found in [2], [4], [7], [8], [9], and [18]. In $[11,12,13]$, it is required that the mapping $\emptyset: P_{1}(S) \rightarrow K$ be monotone but in our paper it isn't.

The mapping $\emptyset: P_{1}(S) \rightarrow K$ is said to be lower semicontinuous if $\left\{u_{n}\right\}$ and $\left\{0 u_{n}\right\}$ are both weakly convergent, then $\lim _{n \rightarrow \infty} \emptyset u_{n} \geqq \emptyset\left(\lim _{n \rightarrow \infty} u_{n}\right)$.

The idea of lower semicontinuity is used in many areas. We would like to have the following result.

THEOREM 8. Let $(X, d)$ be a complete $K$-metric space and $S$ a nonempty closed subset of $X$. Suppose that $T: S \rightarrow X$ satisfies (12), (13), (3) and Condition (A). (12) $\quad 0(d(T x, T y)) \leqq d(x, y), x \neq y \in S$,

(13) $0(t)>t$ for any $t \in P_{1}(S)$, where $0: P_{1}(S) \rightarrow K$ is lower semicontinuous. Then $T$ has a unique fixed point in $S$.

Proof. The proof is almost the same as that of Lemma 1. We omit it. The author thanks the referee very much for his valuable suggestions.

\section{REFERENCES}

[1] N.A. ASSAD, A fixed point theorem for weakly uniformly strict contractions, Canad. Math. Bull. 16(1), (1973), 15-18. 
L2] N.A. ASSAD \& W.A. KIRK, Fixed point theorems for set-valued mappings of contractive type, Pacific J. Math. 43 (1973), No. 3, 553-562.

[3] L.E. Blumenthal, Theory and application of distance geometry, Clarendon Press, Oxford, (1953).

[4] J.C. Bolen \& B.B. Williams, On the convergence of successive approximations for quasi-nonexpansive mappings through abstract cones, Technical Report No. 29 (1975) Unıversity of Texas at Arlington.

[5] D. W. Boyd \& J.S. Wong, On nonlinear contractions, Proc. Amer. Math. Soc. 20 (1969), 458-464.

[6] K. J. Chung, Common fixed point theorems through abstract cones, Bull. Polon. Sc1. Math. (1980), 619-626.

[7] K. J. Chung, Remarks on nonlinear contractions, Pacific J. Math. 101 (1982), 41-48.

[8] K. J. Chung, Nonlinear contractions in abstract spaces, Kodai Math. J. 4 (1981), 288-292.

[9] J. CARISTI, Fixed point theorems for mappings satisfying inwardness conditions, Trans. Amer. Math. Soc. 215 (1976), 241-251.

[10] M. M. DAY, Normed linear spaces. p. 23-24.

[11] J. Eisenfeld \& V. Lakshmikantham, Remarks on nonlinear contraction and comparison principle in abstract cones, J. Math. Anal. Appl. 61 (1977), 116-121.

[12] J. Eisenfeld \& V. Lakshmikantham, Comparison principle and nonlinear contractions in abstract spaces, J. Math. Anal. Appl. 49 (1975), 504-511.

[13] J. Eisenfeld \& V. Lakshmikantham, Fixed point theorems through abstract cones, J. Math. Anal. Appl. 52 (1975), 25-35.

[14] M. A. Krasnoselskir, Positive solutions of operation equations, Noordhoff, Groningen, 1964.

[15] S. Mazur, Uber konvexe Menger in linearen normierten Raumen, Studia Math. 4 (1933), 70-84.

[16] A. Meir \& E. Keeler, A theorem on contraction mappings, J. Math. Anal. Appl. 28 (1969), 326-329.

[17] V. M. Sehgal \& S. P. Singh, On a fixed point theorem of Krasnoselskii for locally convex spaces, Pacific J. Math. 62 (1976), No. 2, 561-567.

[18] S. PARK \& J. Yoon, Remarks on fixed point theorems on star-shaped sets, J. Korean Math. Soc. Vol. 18, (2) (1982), 135-140.

[19] T. Szilagyi \& M. Hegedus, Equivalent conditions and a new fixed point theorem in the theory of contractive type mappings, Math. Japon. 1 (1980), 147-157.

[20] C. L. YeN \& K. J. Chung, A theorem on fixed point and periodic point, Tamkang J. Math. vol. 5, 2 (1974), 235-239.

[21] K. Yosida, Functional analysis, p. 109.

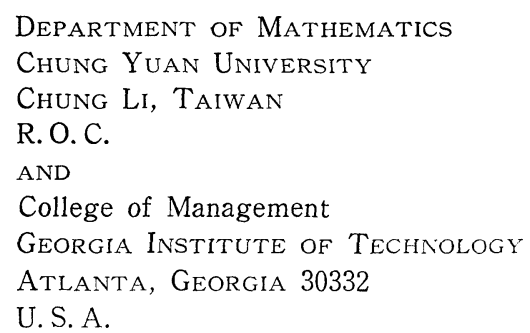

